\title{
AN EXPIATION PROCESS IN A CASE OF SCHIZOPHRENIA.
}

\author{
By henry Devine, Portsmouth.
}

I.

UNDER the heading of les manies de la réparation, Janet has described an interesting form of reaction which he has observed in his psychasthenic cases. ${ }^{1}$ He has shown that when these patients are obsessed by evil suggestions, they are often impelled to give themselves up to some other activities by means of which they endeavour to atone for and to efface the disagreeable thoughts which persistently obtrude themselves. This mechanism often takes the form of a simple compensation, as in the case of the patient who said, "When I am walking and bad thoughts come into my mind, I pull myself up and walk back a step to correct them; it is as if I corrected a mistake in an account book." In other cases the second action which serves to compensate for the primary one is painful and disagreeable in character, and has the appearance of a kind of self-inflicted punishment. Such reactions Janet includes under the term les manies de l'expiation. Thus, one patient mentally promises himself to put himself in prison for five minutes as an expiation for certain indelicate actions. Others, who accuse themselves of blasphemy, of loving their friends more than their family, of having thought of the eucharist in front of a baker's shop, and so on, are similarly impelled to expiate these thoughts by various useless and ineffective acts. Thus, a patient who accuses herself of untruths and immodesty, vows her soul and those of her children to the devil as a punishment; and while such expiatory acts have at first only a personal reference, they soon become generalized, so that she must expiate for an uncle, an irreligious brother, and a politician who died in somewhat unedifying circumstances. She has, indeed, as she says, " rages of expiation for everybody."

II.

During the last eighteen months I have devoted much attention to the clinical study of a patient who has been insane for some twenty years. ${ }^{2}$ As the investigation proceeded, I was surprised to find that the mental activity was almost exclusively directed to the elaboration of extremely complex and fantastic acts of expiation, similar in 
character and origin to those described by Janet in his obsessional cases. This case, however, is a psychosis, and differs from those described by Janet in that the primary impulses or thoughts which have to be expiated assume an hallucinatory instead of an obsessional form; otherwise the expiation process is practically identical. A brief history of the case may first be given.

In December, 1918, Mr. A., a gentleman, age 51, was lodging in an hotel at $\mathbf{X}$. One morning, clothed only in his trousers, socks, and vest, he emerged from his bedroom into the corridor, and, walking up to the chambermaid, he struck himself with his braces, and remarked in a loud voice, "Do you for Christ's sake see me knocking myself ?" On account of this alarming and eccentric conduct the police were summoned, and as the gentleman was found to be insane, he was certified, and he thus came under my care. On admission he was quiet and composed, his chief eccentricity being the tendency to crawl under the other patients' beds. His explanation of such conduct was inadequate. He said he did it "for fun " because he did the same thing as a child. His mind was perfectly clear, however, and he revealed himself as a well-bred man of high intellectual attainments. He conversed about himself in a general way, but not intimately, and he denied hallucinations, though his whole attitude clearly indicated their presence. He talked vaguely and with reticence about "Strengths", discussing various kinds of strength, supernatural and otherwise. He said, when questioned as to his history, that he was the youngest member of a large family, and that there was a considerable gap in age between himself and his brothers and sisters. There had never been much sympathy between them; they had not understood him and had tended to domineer over him. There had been domestic inharmony, and his father had eventually lived away from home. He had for a time been a medical student, but had not pursued his studies to their completion, and he had lived a wandering life on the continent, leading a somewhat precarious existence by teaching languages. He had spent a good deal of his invested capital and had often been in financial straits. At the time he was certified the patient was evidently in low water, as the hotel in which he was staying was of an inferior type.

For about a year his condition remained unchanged. His demeanour was one of excessive and stilted politeness. He would stand up if I entered the room, make way deferentially for me to pass, take off his hat if he should meet me in the garden, and always address me punctiliously as "Sir". The usual lack of emotional rapport between himself and the environment was present in a high degree. His attitude and expression were like a mask to conceal his thoughts and real feelings. His air of exaggerated humility was, however, in striking contrast to the expression of his eyes, which was indicative of a fierce and antagonistic attitude. His general appearance was, in fact, singularly like a Mephistopheles. His attitude reminded one of a prisoner, who, while outwardly displaying implicit obedience to authority, actually regarded his guardians with repulsion and hatred. His phrasing was stilted and precise, and the words of his sentences were carefully chosen. He exhibited various mannerisms and behaved eccentrically. He would bow to imaginary persons, place a cigarette on the ground and make a series of steps towards and away from it, lie on his face, kneel down, or gaze fixedly at the sky.

$$
\text { VOL. II.- NO. } 7 .
$$


He gave trivial explanations for these actions. He would say, "It is necessary that a gentleman should take exercise", or that such actions were not hurtful to others and for that reason " could not reasonably be objected to by. an authority". He afforded no opportunity to penetrate into his inner mental life, and he denied hallucinations in the manner peculiar to the schizophrenic.

In December, 1919, however, the patient said he wished to speak to me privately, and he then opened up freely and told me those facts which it was interesting for me to know.. His statement, in so far as it relates to the hallucinations, may be briefly outlined. In 1902, while reading in his lodgings in a continental town, he suddenly heard loud voices repeating the phrase "Bey, pay 600 pounds!" This, as I found out later, was a blackmailing threat, the 'Bey' being a contraction of the word 'Obey' which he used to his nurse when a child. These 'voices' have been incessantly with him for eighteen years holding him in conversation, and it was the fact that the constant attention which they exacted from him was beginning to "exhaust his brain" that led him to consult me. He said that he feared that if the annoyance continued he would lose his reason. On one occasion he complained to the police and was confined for a time in an asylum in Austria. At first he imagined the voices came from the next room to his, then he felt it must be a trick on the part of people in the street, and finding that this could not be the case, the possibility of hypnotism occurred to him; finally he realized that the experiences must be supernatural in origin and attributable to agencies which he describes under the heading of "Immortal Strengths". It is the activities of these 'Strengths' which it is the purpose of the present paper to consider.

As the patient was often very difficult, irritable, and antagonistic, I did not attempt to utilize the free association method. I contented myself with ordinary conversations, and had to be satisfied with what Mr. A. chose to tell me. Fortunately he seemed pleased to talk, and it soon became evident that the hallucinations were highly organized into a system, and that the case could be regarded as a duplication of the personality. As such we may regard it for descriptive purposes, and I shall endeavour to suggest the significance of these 'Immortal Strengths' by describing, as far as possible in the words of Mr. A. himself, what they said and did, or compelled the patient to do. In the first place it is to be observed that the 'Strengths' are in no sense creative; they give Mr. A. no new information and reveal nothing, but they incessantly throw up the past and interfere with his present thoughts and actions.

" He has gathered from my brain everything I have ever done or remembered", he says. "He is entirely engrossed in my thoughts-a listener informing himself of what I think. He reprimands me for all I have thought or done in a kind of parental authority. It is the rôle of the elderly-father-bishop rolling about in my brain. It is as if my childhood were a book. They tear out the pages, as it were, and accuse me of them all. He gets all these things from me; he weighs me down with my own knowledge. Their talk is a kind of tyranny. Their attitude is one of 
vicious mastery-they say they are greater than God. They like to punish; they will punish for anything $I$ did in my youth. It is simple wilfulness; a whimsical capriciousness, not proper punishment, but just a delight in punishing. He says it is just his will to punish. He keeps me terror bound as if life would terminate in an hour. He strikes me quite capriciously. He is the sort of person who loves to strike without reason. $\mathrm{He}$ is vindictive and revengeful, a mixture of villainy and cunning. $\mathrm{He}$ annoys me for the joy of it; it is a semi-brutal attitude, misused strength. They control of me viciously. He has a cantankerous will against me; he is a continuer of corrections; a getter into vicious states; a brain trialer to see how long I can stand him ; a pernicious authority correcting me as if I were a child of three; a delighter in dislocating things; a seller of me; a blackmailer; a lover of punishment. He is not a creator but a destroyer-a lover of slighting sex moralities. It is a domination and brutality". Sometimes Mr. A. utilizes metaphors to explain his impressions of the 'Strengths'. "He is like a sloshing bull; like a drunken woman. In voice he resembles a big strong man angry with me as if I were a little child. I put the child as much smaller than a child and him as a great giant-in my mind much larger than anything. My mental picture is just strength and a voice. He is like a hectoring schoolmaster whirling a great stick on all around him". At times the 'Strengths' are more genial, a condition which $\mathbf{M r}$. A. aptly describes in the phrase, "When they pretend to be pleased with me their attitude is a kind of letting off of punishment."

We thus see that the patient is in the grip of a very evil forcea kind of personified hatred; and it is of interest to note in passing how effectively this metaphor of size represents his feelings in relation to the 'Strengths'. A similar device was formerly utilized in old paintings, where the king as ruler was represented very large and his inferiors progressively smaller according to rank. The same method of depicting emotional situations of a humiliating and embarrassing kind is also employed in humorous art. At any rate the word-picture of the patient gives us a clear impression of the extent to which these invisible forces control him, and it enables us to comprehend the situation to which he has to adjust himself. As will be seen later, Mr. A. is describing with a good deal of insight an impulse of his own which has determined his reactions to life since childhood, and which has now undergone a process of dissociation.

It will be observed that $\mathrm{Mr}$. A. describes the 'Strengths' as engaged in throwing up his past misdeeds and utilizing them as opportunities for inflicting punishment. Further investigation shows this to be the case, and at the time he confided in me a curious process was going on in his mind. The 'Strengths' were incessantly accusing him of a number of 'offences' which he had actually committed against his relatives and friends in his childhood and youth. That is to say, hallucinatory memories were constantly being revived in the form of reproaches by 'voices' (projection mechanism). I have a 
whole list of these offences which the patient has scribbled down on notepaper. They make a curious collection, and indicate a definite sadistic tendency, though not very serious in themselves. The concrete sexual element is only occasionally in evidence, and then it indicates some tendency to perverseness rather than cruelty towards the sexual object. The majority refer to striking people with a whip, which may have some symbolic sexual significance, but of this I have no evidence. It is not within the scope of this paper to discuss the origin or meaning of sadism as such, but the point I wish now to emphasize is that, as Mr. A. is accused of offence by the 'Strengths', so is he forced by them to go through a series of expiatory acts which he describes as "vagaries of praying". These prayers he has written out, and for each offence he will have to 'go through' a prayer as many as $\mathbf{5 0 0}$ times. One example will make the mental process clear. The patient will go through the fact that he "struck the lady wife of Mr. C. on the face, arms, and feet", by repeating the following expiatory prayer :-

"Hear the prayer of me full of remembrance of my faults against persons and children. I beg pardon of those insolent words and bad woundings of the bodies and parts of the bodies of those persons at those times, and in penitent mind I beg them to forgive me those actions wilfully done of me, and those actions done during wilful anger and brutal, vulgar state of vicious joy of wounding against their bodies."

Here then is the same double process which Janet describes in his psychasthenic cases. There are the evil thoughts coming into his mind in the form of hallucinatory memories, and the compensatory expiatory reactions which take the form of endless prayer repetitions. The cruelty (vicious joy of wounding) component of these offences is clearly brought out in this expiation, and a true sadistic (sexual) colouring may possibly be inferred. It is also to be noted that Mr. A. uses here almost identical language as he does in describing the characters of the 'Strengths', the latter being the personification of the impulse which formerly led him to make these attacks on various people.

We.all remember Freud's famous dictum that the hysterical patient suffers from reminiscences, and the same may be said in respect to Mr. A. The hallucinations are memories of a particular kind, and it must also be observed that the expiations originate like the hallucinations from the early memories of the patient. The 'Strengths' force him to adopt an attitude of complete submissionan infantile pose. Mr. A. makes this clear when he says :-

" There is no end to my repentances. I say 'I beg pardon of these acts of violence' and the 'Strengths' interrupt me. They make me repeat it slowly in a childlike voice. They think it necessary that a mortal should 
pray as a child because his strength is diminished and he is more obedient to them. 'I will be your father, you will be my son', they say."

The expiatory acts themselves are regressive activities, and afford an interesting example of the reanimation of childish beliefs in a patient of high culture.

"They have found out what the clergyman told me, and used it against me. They tell me I have been read against, and they force me to confess my faults and be penitent and to give in to the wishes of those in authority. I knocked people about as a child, and they have read against me. These 'Strengths' are devils who were asked for to be against me for certain wrongs I had committed against certain persons. I take it that these persons instead of having used their own strength against me have got 'Immortal Strengths' against me."

This strange statement is readily explicable. The expression read against is derived from the memories of the patient of the Commination in the Prayer Book, where we read: "In the Primitive Church there was a godly discipline, that . . . such persons who stood convicted of notorious sin were put to open penance, and punished in this world, that their souls might be saved in the day of the Lord: . . Instead whereof, (until the said discipline may be restored again, which is much to be wished,) it is thought good, that at this time (in the presence of you all) should be read the general sentences of God's cursing against impenitent sinners."

The meaning of Mr. A.'s statement is thus clear. His father, mother, sisters, and brothers, those, in short, whom he had wronged and insulted, have handed him over to the 'Immortal Strengths' for punishment, The delusion is a regression to the childish belief, "The devil will take you if you are naughty.' The idea is included in most religious systems, as also in mythology. An almost identical situation is described in Eschylus' Eumenides. When Orestes murdered his mother, Clytemnestra, her ghost exhorted the Furies to pursue and torment her slayer, and it is of interest to observe that the character of these Furies is identical with that of the 'Strengths'. Their aim is not to benefit or regenerate their victim, but they are themselves evil and delight in the hatefulness of their office. Like the 'Strengths', it is not "proper punishment" but "just a delight in punishing". *

It is clear that the 'Strengths' are father substitutes. The father is revenging himself for the thoughts and actions committed by $\mathbf{M r}$. A. against him in childhood. And by father is meant those who were in authority over the patient as a child-especially the elder brother, of whom he has an intense and irrational dislike. The patient did

* I am indebted to the Rev. W. H. David, Vicar of Portsmouth, for drawing my attention to the resemblance between the myth and the psychosis. 
not kill his father, but he had death wishes in respect to him, and for these he has to expiate as for actual offences (omnipotence of thought). All these facts are derived from the statements of the patient himself, as the following quotations show:-

" There are two of these 'Strengths'-father and son. The father has gone in for some months now. They take on the voices of people remembered of me. He poses as my father because I said a child looks up to his father not because of his love but because of his superior strength. It originated first because I said I did not mind if my father were dead. He has got punishment on the brain. He likes pretending to be my brother when he was in a domineering way with me. It's absurd to pose as my brother when I am not a child but a man of fifty. He even uses his phrases and says, 'You are a person to be mastered', or uses domineering-like sentences to me such as, 'Why don't you take off your hat more respectfully to the gentleman?"

I shall now endeavour to show the further development of (1) the offences, (2) the expiations. Both these assume increasing complexity and afford a striking example of the process of displacement. It will be seen that the 'Strengths' do not confine themselves to past offences, but seek new and increasingly ridiculous occasions for punishment and impose increasingly fantastic modes of expiation, so that the inner mental life of the patient comes to consist of a perfect frenzy of accusations and expiations. Like Janet's patient, Mr. A. has " rages of expiation for everybody."

1. The Development of the Offences.-The patient explains that the 'Strengths' are not content with making him expiate for past offences, but they extract from his brain all thoughts of an evil kind he may have now, or may have had in the past about people, and punish him for these. They go further than this. They endeavour to trick him into thinking evil, and then punish him by forcing him to "word to him" or "apologize in extensive form". The patient explains this as follows :-

" $\mathrm{He}$ is getting particular now, and my thoughts cannot always be Christian or pure. I must sometimes have anger, distaste, or ill-will against mortals. They wish my mind to be an effervescing stream, always bubbling up to them. If I am like that I can avoid their anger, but they are tricksters, and make me think evil in order to find fault with me. I can understand a mortal may tell me to sit down and have no blasphemous thoughts for an hour, but the gentleman would not make me sit down and force me to think evil in order to find fault. The only person who could get on with them would be a perfectly thinking mortal. It seems to me he wishes to keep my mind in a high state of Jesus. It is walking about in an excessive state of purity, presenting one's face to be knocked about. He insists I shall have no bad thoughts of people-burning, growing old, or strangling - and yet he tricks me into having them. He makes me act as a repenting person, regards me as a person who must be repentant for all his acts and thoughts since childhood, and yet induces 
me mentally to commit criminal acts. This attitude of making me good is incompatible with making me think evil."

The methods by which the 'Strengths' trick Mr. A. into criminal admissions are ingenious, and are thus described by the patient :-

" He (the 'Strengths') is still on with wordings about lifelessness. This is what happens. He says to me, 'Do you know Mr. S. ? Would you like his wife dead, murdered ?' I may thoughtlessly reply 'Yes', just as I might say I wish a woman were dead who annoys me in the street. Or he tricks me into saying 'Yes'-he talks about something else to which 'Yes' should be said, and then suddenly darts this question at me, and I say 'Yes' without thinking. The 'Strengths' then threaten me and say, 'There is willingness on your part that the lady should be out of life', and make me go through wordings (expiations) as a penance."

Not only do the 'Strengths' throw down such questions to the patient " 2000 times a day", but they twist almost any thought which has the remotest association with death or destruction into a wish to commit a criminal act. Thus not only do such words as animosity, disease, strike, kill, destroy, and burn become "points of danger" for the patient, but apparently harmless words such as departure, arrival, growing old are given sinister meanings by the 'Strengths', and necessitate expiatory acts. These words are distorted into meaning that Mr. A. desires someone's death on the grounds that departure implies "going out of life", arrival " reaching the next world", and growing old that the person will be dead before long in all probability. Indeed, the patient can scarcely think, see, hear, or do anything without his experiences being twisted by the 'Strengths' into a death-wish. The following shows this clearly, and will suffice as an example of a characteristic conversation with the 'Strengths' :- -

The patient is eating a pear and squashing it with a fork.

Strengths : "Is the pear alive?"

Mr. A... : "No, it is a fruit."

S. : "Is it a body?"

A. : "No."

S. : "Is there an insect in it you may squash?"

A.: "There may be."

S. : "There is a willingness on your part that the insect should be squashed. Apologize to the insect, its wife and family, etc., five hundred times."

It is apparent that the thoughts and actions of the patient must be extremely restricted if he is to avoid punishment. As a matter of fact, practically his whole time is occupied with the apologies or expiations which the 'Strengths' regard as necessary. The patient does, however, make some attempt to avoid any occasion for punishment. He will try, for instance, not to think at all. "I try to keep my mind a blank," he says, " and not to think to him. Unless my 
mind is like an empty glass he is constantly asking questions. A kind of sleep or closing of the mind, like a tank with water flowing round, is what I need." More childish methods of evading punishment are sometimes employed by the patient. The 'Strengths' accuse him of " Upsetting a wheelbarrow, murdering a cat, and cutting off a baby's head." "I excuse myself", Mr. A. explains, "by mentally showing him that the barrow is upright, the cat is alive, and the head is on the baby. He is excessively pleased at this, and goes into his childish . states." A less fantastic method adopted by the patient sometimes is that of thinking of ideas which are in direct contrast to those suggesting death and destruction. Thus he will repeat to himself such sentences as the following :-

"The flowers are growing,

The leaves are trembling in the wind,

The sea waves are moving,

The sand waves are moving,

People are passing by."

These phrases all suggest life, movement, and growth, and they have the same purpose as the attempt which people often make to distract their minds from painful reflections by thinking of pleasant things. And they are just about as successful, as the patient himself recognizes when he says :-

"I always say in the early morning, "I wish all mortals on the face of the earth, born and unborn, to be alive this day : all in life, all in luck', and I think this should clear me for the day. Yet in the middle of the sentence he interrupts me and asks if I am willing that someone should be knocked down, killed, or strangled. If I hesitate, he interprets it that I wish these things done. And if I say 'Yes' he makes me apologize to the man's wife and family."

2. The further Developments of the Expiations may next be traced. It will be seen that just as the 'offences' become more numerous by the process of displacement, so a parallel process occurs with the expiations, which become increasingly intricate, fantastic, and complex. The prayer expiations become intermingled with, and replaced by, exceedingly complex mental activities which the patient calls wordings or apologies. These are not confined to the person supposed to be offended, but must include the whole family group, as shown by the following :-

" $\mathrm{He}$ is always making me word about lifelessness. If he tricks me into consenting that a woman should be murdered, he makes me go through wordings as a penance. The wordings are an excuse to be begged off of the woman. They are like the prayers-just built up of words. He makes me say, "They are mortals. I beg pardon of that sentence of words with kill in it, for which I beg to apologize. I beg pardon of the lady, her gentleman husband, the uncles, aunts, sisters, brothers, and cousins of 
the lady ; the uncles, aunts, sisters, brothers, and cousins of the gentleman husband; the sons and daughters of the lady, the babies of the lady, the babies of the lady not yet born. I beg pardon of the babies of the uncles, the babies of the aunts, the babies of the sisters, the babies of the brothers, the babies of the cousins on the lady's side, and the babies of the uncles, etc., on the gentleman husband's side. The grandfather on the lady's side, their sons and daughters growing up, and their babies ; th: grandfather on the gentleman husband's side, their sons and daughters growing up, and their babies; their relations and co-relations, the son's cousins growing up and their babies'. Thus he makes me go a-begging pardon of the woman."

The above may be regarded as the apology unit, and though this might appear sufficiently complex when repeated a large number of times, in actual practice the task of the patient is infinitely more elaborate and fatiguing. The 'Strengths' impose all kinds of additional conditions upon the patient as to the form of the apology. Thus the social position of the person supposed to be offended has to be indicated in the phrasing of the apology :-

"He divides them into ladies, semi-ladies, and common people. The semi-ladies or would-be ladies are those who are always particular to be regarded as ladies and referred to as such. He is particular that I make the right distinctions in wordings about these people. It is just a domination and brutality."

Furthermore the apology has to be made without a single mistake, in a particular tone of voice (mentally), and without any interruptions. It has also to be preceded by the following sentences, which set out the various conditions imposed :-

"With refusals, fully leisure (or at the fastest rate), without additions, without omissions, without giftings from them, without payment of wishes, without questions; no lies or lies thrown in; with names of persons, names of things; with proper positions of body, head, and neck; with countings, without beggings-off, without re-beginnings."*

Any mistake made by the patient nullifies the whole apology, and he has to perform the expiation over again the requisite number of times, adding to it a reference to the error he has made.

*With refusals : apology must imply refusal to commit offence again.

Fully leisure: apology must not be gabbled through.

Without additions or omissions : nothing to be added or omitted.

Without giftings and payment of wishes : no favours, such as being allowed to stop apology at bedtime.

Without questions : no arguments with 'Strengths'.

With names of persons, etc. : person or thing offended to be described in apology. Position of body, etc. : must make apology standing in some uncomfortable position. With countings : must repeat apology the requisite number of times.

Without beggings-off : must not asked to be excused on score of fatigue.

Without re-beginnings : must not start again until apology is quite finished. 
"If during the apology I think the word tree, it has to be included in it. With the "Strengths' it then becomes an improper sentence, and I have to say, 'I beg pardon of the lady without the word tree accidentally thought of me, etc.' If I make a mistake he requires me to use more wordings. Even if I cough it has to be taken out of the apology."

The last feature of the expiations which $\mathrm{I}$ wish to emphasize is that they are not forced upon him to benefit or improve him, but solely to humiliate him and reduce him to a state of complete submission. This is done more effectively by what Mr. A. describes as a thickening of the apology-a process which greatly complicates and lengthens it. This term means that the apology must be couched in phrases which imply " an extensive exaggeration of the offended person's position", and the expiation then runs as follows :-

"I beg pardon of the gentleman for that for which I beg to apologize, the highest and greatest in the Empire, the richest minded, richest in authority, and very well rich; I beg pardon of his lady wife of most beautiful framework, well dressed at all times, richest minded, etc."-proceeding through the whole family group, as previously shown.

Mr. A. is not without insight into the absurdity of his expiations, though he is forced to carry them out, for he says :--

"It is just will shown in the form of orders. It is perfect rubbish for a man of my age. It is just like a schoolmaster or father making a boy recite lessons. It's mastery of me he wants. He probably gets roordings from my childhood when the teacher made me say 'Beg pardon' and then turn round to the class and repeat it."

It must now be observed that expiatory activities are not the only forms of punishment to which the patient is compelled to submit. If he makes mistakes in his apologies the 'Strengths' often knock him about and cause him to have certain bodily experiences of a painful character. We have thus an interesting series of kinæsthetic and conæsthetic hallucinations, a few examples of which may now be given :-

"He gets into peculiar sudden states of mind when there is a tremendous rage against me. They knock me about as if I were a baby-knocked about and put to bed. They give me pain in my body and twist my toes. They give me a feeling of crushing in my shoulder blades. It is wilful strength in the form of pains. They do this because they have got from me what I have seen-a deformed and twisted beggar huddled up in the street. They struck me in Paris for the first time; they struck me in the form of a battery. He showed this form of strength because he knew I had put coins in a machine which gives electric shocks. At times he says he will strike me as I have struck others. I have the sensation of being struck in the bones or flesh. They do not often knock me over in their angered states; they merely apply strength. They give me the sensation of being crumpled up; the bones and all have that feeling-not broken but crumpled up .. a sensation of becoming a bag of powder." 
A particularly curious phenomenon is an hallucinatory pregnancy phantasy of which the patient sometimes complains. He describes this as follows :-

" He rolls me about. He kind of distends me like a ball inside; like a baby. I tell him that I am not the kind of person who can conceive anything. I only know of what happens from what women tell to men; from what I know of distensible pressure. I know it from diagrams-I was a medical student once. They are sensations $I$ have thought of-rocking-horse movements, like the piston rod of an engine. All this arouses tremendous irritability of the mind. It is as if I took hold of a mortal's chair and rocked it. It would annoy, disturb, upset. He demands all in excess of what the brain can do. He reproduces in me the sensation of being caught hold of, as if in a crowd at the theatre, and forcibly removed by an irascible person."

It will be noted that just as the 'offences' include hallucinatory revivals of past experiences, and just as the expiations are regressive revivals of similar activities carried out in childhood, so are these kinæsthetic hallucinations reproductions of former perceptual experiences which to the patient, because of his peculiar tastes, were a source of pleasure and interest.

These phenomena are very frequent in our insane cases, but it is not usual to find their origin so clearly explained by our patients as they are in the present instance. These kinæsthetic hallucinations bring into prominence the motor and organic aspects of thought processes. They show that hallucinations are not merely thoughts coming into the mind, but they include implicit adjustive activities to an imagined situation which may at any moment issue in overt behaviour (impulses). In perception the stimulus comes from without, in hallucinatory experiences it is derived from an organic need and comes from an urge within. When Mr. A. saw the twisted beggar, his total experience was not confined to a visual perception of the man. Since the experience harmonized with a perverted need, it would be pleasant to him and would provoke agreeable viscera disturbances (emotions). It would provoke, also, nascent movements and attitudes corresponding to the twisted form of the beggar himself, and the patient would identify himself, physically and mentally, with the beggar, and would experience, as it were, a kind of sadisticmasochistic thrill as he looked at him. The hallucinatory revival is physically an actual revival of this thrill just as it occurred in his previous experience. "They give me pain in my body and twist my toes", the patient says, and in so doing he is describing the kinæsthetic and organic disturbances produced by the nascent movements, tensions, and organic disturbances resulting from the stimulus of his perverted craving which has assumed hallucinatory form.

It is of interest to observe that the 'Strengths' do not confine 
their physical punishments to a revival of remote experiences extracted from the brain of the patient, but they utilize his experiences of the day. One instance may be given. "If during the day I see a gardener cutting the hedge with sharp scissors and I step on a stone which hurts my foot, he will later use these things against me and will reproduce in my body a sharp-scissors-stone-pain."

At times the 'Strengths' get into conditions of extreme irritability, especially if the patient attempts to thwart them. Such experiences Mr. A. describes as follows :-

"They get into excessive states of mind-a mixture of mad baby and half-mad woman. It's extraordinary what they produce-fantastic rubbish, wild imaginations, not of place or things. It's a kind of bordering on anger. I couldn't imagine such rubbishy fantastic stuff. It's a kind of epileptic fit-moving my body and making my muscles quiver. It's extraordinary when he hits out. It's all irrational movements; I cannot describe it in words-only movements. It's like a top at the end of its gyrations, translated into a lot of wordings. It's a sort of bad type of diminutive woman - a sort of dwarf, an object of derision."

In this word-picture the patient furnishes an excellent description of the diffuse physical excitement or suppressed hatred and anger associated with the thwarting of an imperative, instinctive need. Another comment suggests itself. If this emotional excitement had discharged itself through motor channels in overt movements it would appear that something would have resulted very like an epileptic fit. The thought is suggestive in light of the view expressed by Stekel that an epileptic is to be regarded as a repressed criminal and the convulsion as a substitute for the criminal act. While such a view is in all probability applicable only to some convulsive episodes, the association between epilepsy and sadistic tendencies has often been noted, as, for instance, in papers by Maeder, ${ }^{3}$ Ernest Jones, ${ }^{4}$ Read. ${ }^{5}$

It must now be pointed out that the hallucinatory experiences in this case are not exclusively implicit activities, but they find expression in overt impulses and movements. We may again refer to Mr. A.'s statements :-

"They add strength to my limbs. I put my hand on a man's shoulder, and they make me hold with added firmness to hurt him. It may be that the 'Immortal Strengths' put strength in me to hurt him ; or they mentally hurt him; or they make him shout so that I shall think I hurt him. I keep from sharp instruments because for mischief they turn it on my hand (masochism). They make a needle prick me, and if I had it in my hand they might make me run against a mortal with it. They give me the sensation of my digging my nails into my.palm. Mortals might explain it and say it was my habit to wound myself-a self-wounder. If I put my hand to my head he makes me strike myself. It does not matter with the soft hand, but there might be a hammer in it; and if I take a stick he crashes it on my foot." 
Curiously enough, when Mr. A., as sometimes happens, destroys a mattress or some of his clothes, he always protests it was an accident and becomes highly irritated with me, and he is inaccessible and sulky for a few days. Thus, when once he tore his pyjamas, he explained :-

"I scratch my shoulder; then I catch hold of the skin and muscles, half scratch, half pull; the stuff is weak and goes. It is a little-irritable spot on my shoulder. This doing of mine has been done for years."

The hallucinations do not only determine movements, but they tend to provoke attitudes and muscular tensions :-

" He is fond of moving organs of my body. He likes to hold limbs in fixed positions, or to keep them still when they are about to be moved. He keeps me in a position of standing with my hands and arms in a position of discomfort. He gets it from my brain that it was done of me at school."

It will have been observed that the 'Strengths' impel Mr. A. to do those very things that they punish him for-injure other people, and so on. The patient recognizes this and explains :-

"I do not know what they will force me to do. They lurch me against plate-glass windows, and I have to keep away from the gentleman here because they make me strike out at them."

He believes, also, that they could endow him with their own strength and would use him for their own nefarious purposes if they wished :-

".He would put me in a position of great power, but he would use me for producing evil-nefarious strength, crimes, murder, committing of crimes of a higher type than yet known to mortals. I could crunch up people like tissue paper. They suggest I should create a war in the Universe. This is an absurd enlargement of myself. I know nothing about war, directing armies, the commanding of soldiers. They induce me mentally to commit criminal acts; they would make me a Napoleon among criminals."

We here detect the notion of omnipotence in these 'Strengths', and this, indeed, is what Mr. A. believes them to be: "They are enlicensed persons who can do what they will without interference from God". At times they appear to fuse with the personality of Mr. A. himself and he speaks with their voice, revealing the depths and terror of their power. On one occasion he was beginning to grow irritable with me, and he suddenly said with a look of intense hatred, "If a mortal offends them he will be struck; he will not get up again; he will go black-gashes on the head; the mortal will disappear if they use their strength against him". Then the patient recollected himself and muttered, "I shall have to go through that", and it was interesting to observe that he was exclusively occupied in prayer expiations for several days after this incident. Mr. A. gives numerous 
instances in support of his view that humanity is controlled by the 'Strengths', and when these incidents are examined they are found to be similar in character. Briefly it may be said that any situation which irritates, humiliates, or makes a person look ridiculous, and any accidents, crimes, misfortunes, or cruelty, Mr. A. ascribes to the malicious influence of the 'Strengths'. A few examples will make this clear :-

An excited lady in the street: "They rule all mortals and produce effects upon them. A lady went round and round in the middle of the road shouting at the top of her voice. I thought this is not the kind of thing a lady does. I attribute it to them. Ladies do not turn round and round in great circles in the road and then go home. It is preposterous." Mr. A: * recognizes, however, that the incident is susceptible of other explanations and adds, "Another mortal might have said that she was annoyed of certain doings in the street."

Some mistake about the time in an hotel, etc.: "He likes dislocating things. He will make everyone get up at five in an hotel and be very busy. I asked the maid what had happened. She said she did not know and could not understand it. It is a kind of enchantment of people. In the office he makes the wrong papers be delivered to people, and he forces people to sign papers with signatures of a fradulent kind."

Injuries to children in the street: "He behaves like a child because I once said I was fond of them. Especially holding them. I have held children dead and alive in my arms. They like romping with children, but against this is the throwing down of children. They often do this, and I have seen some who were injured of the gravel. He threw them down to see if I would be sorry or commiserate with them. To stop him at times I have had to try continual talking to keep him off the subject. In such cases I have carefully ascertained that there is nothing to cause the children to fall - an obstruction or a stone. The subject first came up when I was watching the children coming out of school-a barrier was placed outside the gate. He was very inquisitive about it, and I explained to him it was to prevent the children from destroying themselves by rushing straight into the street. He amuses me very much at times by placing a lump of earth heaplings in the way-people fall into them and get covered with mud. At times $I$ have seen him remove gratings in the streetpeople fall into the holes."

Hallucinatory conversation about man on ladder: "If I see a man on a ladder he will say, 'Is it safe ?' I tell him that I am not interested, but he insists I shall stand there and watch. I stand there for a few minutes and say, 'I think so but of course it may fall.' As I walk away he says, 'Look back to see if he is safe.' If the man falls from the ladder it is not my fault; he has thrown him down, but yet he says, 'You wished him to fall. If you had not thought he might fall you wouldn't have given me the idea of knocking him over.' He makes me responsible."

\section{III.}

I have given a somewhat detailed account of this case because it would seem to include features of considerable psychiatric interest. 
It is not often possible to gain an extensive knowledge of the inner mental life of patients of this type. As a general rule we only obtain glimpses of the mental processes which determine the reactions of the insane, but here it has been possible to elicit details which make the strange behaviour of the patient quite intelligible. Mr. A. presents outwardly the usual characteristics of many of the insane in our asylums. He is solitary, out of contact, scarcely ever speaks voluntarily, and sits hidden away in corners for hours together; he grimaces, is manneristic, exhibits stereotypies and unmotived impulses, has an attitude of constraint, and mutters to himself. On the surface his reactions convey no meaning, and it might well be supposed that there was considerable deterioration of the personality. Yet this was not the case. The patient is extremely intelligent, of good memory, and even able to comment upon the absurdity of the life the 'Strengths' compel him to live. The inner mental life reveals an unexpected richness; there is no diminution, but rather an excess of mental activity, and the patient's lack of contact with his environment is in a measure due to the fact that his interest is almost exclusively directed to a purely personal matter which imperatively demands his attention. Mr. A. is, indeed, a very busy man, and to apply the term dementia to such a case would obviously be unsuitable.

The next fact of interest which emerges from the study is that the whole symptom-complex is determined by and secondary to the basic process of dissociation, and since this splitting of the personality is the fundamental psychic lesion upon which the clinical development of the case depends, Bleuler's term, 'schizophrenia', would seem to be that most suitably used in reference to it. It will have been observed that the psychosis commenced many years ago with hallucinatory experiences (dissociation), and it was only after a time that the patient, having explored every other possibility, came to the conclusion that his persecutors were supernatural beings, and he then regressed to rationalizations based upon his early beliefs in order to account for his unaccustomed experiences. And not only the delusions, but all the reactions of the patient develop naturally and logically from the fact that part of his personality has become dissociated. Thus we may say as a clinical fact that all the symptoms are secondary to the primary state of dissociation; that they are psychologically determined; and that, given the situation in which the patient is placed, his behaviour is quite to be understood.

Since the dissociated elements were not isolated and fragmentary, but were highly organized into a definite hallucinatory system, it has been possible to gain some insight into their origin and nature, and more especially so as the split-off mental processes take the form of a clear-cut and definite secondary personality-.-the 'Immortal 
Strengths'. We estimate the character of an individual by his speech and actions, and from the account which has been given of the activities of these 'Strengths', it is apparent that they are expressive of a personality of primitive type of development, of unlimited strength and of unbounded egotism-savage, cruel, ruthless, aggressive, and destructive. The predominating traits are an overwhelming lust of domination, a callous indifference to suffering, and a delight in the infliction of pain. The hallucinatory content exhibits a definite uniformity of theme, and it is exclusively concerned with subjects relating to death, violence, and crime. There is here not merely a tendency for hallucinations to occur, but rather a tendency to experience hallucinations of a particular kind. The images coming into the mind in dissociated form are thus not haphazard, anarchical, or indifferent; whether they are derived from actual memories or are aroused as associations of perceptual experiences, they are always consistent in character.

The definitely selective character of the morbid process is perhaps one of the most interesting facts elicited by this study, and it enables the conclusion to be drawn that the dissociated personality is expressive of an impulse in the patient which finds its satisfaction in acts of cruelty, homicide, and bloodshed-" a vicious joy of wounding" which includes even such a perverted need as "the excessive maiming of animals". This frenzied pleasure in indiscriminate acts of cruelty has already been referred to under the term sadism, and I think this most suitably includes its activities as a whole. It is not here proposed, as previously mentioned, to discuss the origin or significance of sadism as such. The details of the early life of the patient are too scanty to justify such an attempt. To what extent the love of cruelty, teasing, and irritation here personified by the 'Strengths' is to be regarded as a deviation of the sexual aim. I do not know. The patient barely referred directly to his sexual life. The basic need embodied in the 'Strengths' appears to be more a lust for power than a form of sexual satisfaction, but any discussion of this subject would necessarily pivot round what is meant by and included in the term sexual impulse. I feel that this need is something more fundamental than even sex, which is here a component rather than the need itself. Such terms as Schopenhauer's will to live and Nietzsche's will to power come into the mind in reviewing the activities of these 'Strengths', and the instinctive craving they personify might be interpreted, in accordance with Adler's theories, as the outcome of an infantile struggle for power (" der männliche Protest"). As I wish to discuss this case in its broader psychiatric implications I will not further refer to these delicate matters, but will endeavour briefly to expand the view that this sadistic trend, this vital impulse expressed in the form of hatred and 
cruelty, has been the determining factor in the formation of Mr. A.'s character, and that the actual psychosis is only a further stage in its development.

In support of this view a few details of the early history and character traits may be given. From his early childhood the existence of some abnormal trend in his character became apparent. He was always difficult. He behaved as if every man's hand were against him; he was intensely suspicious, secretive, obstinate, aggressive, and self-willed; he showed extreme irritability at any attempt at control, and he developed an intense hatred of his family, his teachers, and, as he went into the world, the whole of humanity. At times, even when grown up, he exhibited episodes of passionate violence against his relatives, thereby causing them much anxiety and distress. Perhaps, however, it is from the content of the hallucinatory memories that we gain the most insight into the early sadistic tendencies of the patient. There are the 'offences', or memories of actual acts of violence; there are the kinæsthetic hallucinations which betray a morbid pleasure in the sight of suffering; and there are the death-wishes and acts of childish destructiveness which the 'Strengths' continually 'throw up' at him. All these trends prevented the patient from adjusting himself to life. His erratic behaviour forced him to relinquish his early career, and he went through life a solitary, restless, uneasy man, hating humanity and the world in which he lived.

It is thus clear that a strongly sadistic tendency had existed since childhood, and that it had exerted an important influence upon the actions of the patient. I would now stress another feature in the make-up of Mr. A. of some significance in relation to the content and structure of the psychosis. I refer to the primitive and almost savage simplicity of his emotional attitude. The patient is, and apparently always has been, utterly devoid of affection, sympathy, kindness, and altruism; he aggressively repudiates the right of anyone to interfere with him, even for his own benefit, and he accepts gifts ungraciously ; he regards all the higher social sentiments with contempt and suspicion; and he thinks human beings should be 'like bits of iron'. I have already pointed out the resemblance between this psychosis and the obsessional neurosis. And this resemblance is indeed close both in respect to pathology and structure. There is a similar dual process in each ; the evil impulses, ultimately derived from hatred and sadistic wishes, and the complementary protective measures expressed in the form of expiatory and ceremonial activities. The two types in some respects are in striking contrast, however. Mr. A. is aggressive, hostile, manifestly hating, and unable to co-operate, while the psychoneurotic is sensitive, gentle, self-depreciatory, and willingly co-operating because of his need for help and reassurance

voL. II.-NO. 7 . 
These differences in make-up would seem to depend on the fact that in the psychoneurotic the hatred impulse is repressed by a reactionformation taking the form of sympathy, pity, and sensitiveness to pain and suffering, whereas in the case of Mr. A. the development of these higher social sentiments is conspicuous by its absence. The anti-social sadistic trend would here seem to have been inhibited by the crude instinctive tendency to submit to the will of the herd. Such reactions as horror and shame to evil thoughts or impulses seem to have been foreign to the character of the patient, and we may perhaps say that this gives the psychosis the note of remorse and retribution rather than that of repentance and forgiveness. The most deeply ingrained and primitive attitude to the world is one of aggression, hatred, and hostility. The world is something which menaces and threatens; it is something to be overcome in the interests of self-preservation. A similar reaction occurs in the child when its self-assertive impulses meet in the parental inhibitions an obstacle to their free expression, and it may be true, as Freud has said, that hate rather than love represents the earliest attitude to the outside world. It is just in this way that Mr. A. has always regarded the world, and it is for this reason that I would express the view that the psychosis is the outcome of an arrest or fixation of the instinctive and emotional life at a primitive or infantile level.

The influence of the father in the determination of the emotional attitude of the child pervades the case. The whole psychosis is, indeed, an exquisitely subtle criticism of, and comment upon, the parental rôle. The childish attitude of Mr. A. to his father was clearly one of hatred. We know nothing about the father, nor have we any intimate details of the early life of the patient; but the content of the psychosis makes it certain that rightly or wrongly he appeared to the patient as a sinister figure of enormous strength who not merely punished but derived pleasure from so doing. And as the patient grew up he viewed the world from the same angle-the father dominates his whole life. For Mr. A., human beings, organizations, the Church, police, governments, and nations seemed to find their highest satisfaction in viciously imposing their will on others. This is the guiding principle of human conduct, and all sentiment is so much camouflage. Every human being strives to become an 'authority' in order that he may ruthlessly dominate his fellow creatures. It is interesting to observe, moreover, how the father-complex determines the philosophy of the patient. He broods on the notion that the tendency throughout nature is for the strong to exterminate the weak ; that in consequence many animals and races have become extinct; that even in plant life the plants are destructive; that "they absorb more nourishment than they need, for the superfluous satisfaction of 
their stomachs"; that "they crunch up insects for the joy of destruction" ; that by this destruction "they increase their strength and intellect at the expense of others" ; and that "these destructive activities are equal to the destruction of 100,000 men." Thus the patient erects a god in the image of his father, and in so doing he perhaps affords an interesting example of how our scientific views are apt to be influenced by our emotional attitude to life.

It must next be observed that implicit in this attitude of hatred is an attitude of admiration. The father, and by the process of displacement the whole world, is an object of hatred as "Strength and a voice" ; but he is also an object of admiration to whom it is a pleasure to submit in virtue of his strength-" a child looks up to his father not because of his love but because of his superior strength." In this dual attitude we see the germ of ambivalency in the sadistic impulse which reaches its culmination in the psychosis. The father and his later substitutes become the ideal as well as the hated oppressor, and inasmuch as this ideal is unable to find expression in appropriate sadistic activities, the patient obtains satisfaction by an attitude of masochistic submission. It is interesting to observe in conversations with the patient how he gained a wealth of knowledge of the underworld of crime, and also of the methods of the police in stamping it out. He derived equal satisfaction from the contemplation of each aspect of social life. This dual attitude found a curious mode of expression in the pleasure the patient used to derive from standing near a policeman to look as if he were guilty of some crime. $\mathrm{He}$ thereby found sadistic satisfaction such as he would have experienced in actually committing the crime, and a masochistic satisfaction in submitting to the penalty. Thus there is here a double process of identification, and Mr. A. punishes himself for his own crime. The same ambivalency characterizes the attitude of the patient at the present time. To myself as the 'authority' who is responsible for his detention his attitude is one of masochistic submission, shown by a subservient politeness, from every detail of which he plainly derives much satisfaction; combined with this, however, is an almost inhuman hatred which peeps out in every direction and which embodies all kinds of death wishes-wishes for which he has subsequently to expiate.

Here then is an individual who, since childhood, had been the subject of a perverted instinctive craving which prevented him from harmonizing with life and which kept him in a state of uneasy tension. Like all instinctive needs, this craving would urge the patient into appropriate activities leading to its gratification, but in this case its anti-social character would render its free expression impossible. A man cannot go about the world " committing crimes of a higher type 
than yet known to mortals". To a certain extent no doubt the sadistic trend was partially sublimed in cultural interests with a strongly sadistic colouring, and it was also able to find an outlęt, a kind of strangled expression, by means of phantasies, appropriate perceptual activities-e.g., the beggar in the street-and occasional acts of explosive violence. We may suppose, then, that a point was ultimately reached when the accumulated energy of this perverted biological impulse was unable to find an adequate outlet, and the development of hallucinations is to be regarded as the final break at a moment of a too severe tension. The hallucinations occurred many years ago, and any special factors determining their occurrence cannot now be elicited, so that we must confine our views to the general statement that the sadistic tendency assumed hallucinatory form by virtue of its own inherent elemental force. In hallucinatory form the abnormal craving is free to expand. Before the development of the psychosis the patient had to seek out situations which would feed his abnormal trend; in the psychosis these situations are mechanically and incessantly provided by revived memories of past experiences. The 'Immortal Strengths' are the personification of a purely primitive and instinctive need. It seems hardly correct or appropriate to apply any ethical term such as evil to this craving. It is just an elemental impulse seeking its own inherent ends. It is a-moral rather than evil ; and perhaps the 'Strengths' afford us some insight into the behaviour of a human being unrestrained by any social, ethical, and moral inhibitions. Mr. A. expresses this aptly when he describes them as "enlicensed persons who have been given permission to do what they will without interference from God". Perhaps most human beings have sometimes sighed to be enlicensed persons even for a little while, and perhaps, also, there is a tendency at the present day for this sigh to become articulate.

The 'Immortal Strengths' are completely irresponsible, an attitude seen more particularly in the childish states they sometimes assume. "Both of them", the patient says, "take the part of my children. These children are of tremendous strength-greater than God." In this infantile pose the 'Strengths' are utterly impossible, capricious, and irritating. They make incessant demands, play all kinds of malicious pranks, have to be fussed, amused, taken out to tea shops, the theatre, and so on. They make Mr. A. thieve, forge cheques, give them large sums of money, build houses for them, and so keep him in a constant state of irritating activity. At times they make the patient do even stranger things, such, for instance as standing on his head on the sloping roof of the villa 5000 times-as Mr. A. remarks, " an absurd thing to be done of mortals". Naturally these activities are only performed mentally, and it is of interest to note 
how subjective preoccupations of this kind attain a greater realityvalue to our patients than do environmental situations. As : has already been shown, the 'Immortal Strengths' are to the patient omnipotent, and they express in this, as in every other way, all that the sadistic trend of the patient would urge him to be and do. They are wish-fulfilments; a reincarnation of the father in the form of a god.

The reactions of the patient to the 'Immortal Strengths' afford, I think, a striking example of the ambivalency of the sadistic impulse. It has often been pointed out that sadism and masochism occur constantly together, and in this we we he the active, aggressive component of the sadistic-masochistic impulse turns against the subject, compelling him to submit to all kinds of pain and humiliations. It is usual for one of the ambivalent tendencies to become increased when the other is inhibited, but here the condition of dissociation permits us to observe the ambivalent tendencies in operation at the same time. The expiations show how the masochistic attitude is exactly opposite to the sadistic one. The two form a perfect contrast. The 'Strengths', with their qualities of omnipotence, aggressiveness, pleasure in cruelty, and devilish criminality, impose on Mr. A. an attitude of passive helplessness, humility, slavish submission, and a perfection of thought and action (an excessively christianized state). The patient is forced to be subservient to those whom he despises and would gladly exterminate. The 'Strengths' tell him he must take the "lowest state of position", and that he must behave to everyone around him as if they were princes and people of great wealth. He is compelled, even, to abase himself to insects and jellyfish-and apologize to them in a mood of the utmost humility. And there is no doubt that the expiations are a source of strange pleasure to the patient. His intense interest in the details of his punishments, the pains he takes to carry them out with accuracy, and the expression of almost lustful pleasure on his face as he busily occupies himself with his ceremonial acts, all indicate that his tasks afford him a kind of unholy satisfaction. When one talks to him his manner reminds one of a child who is compelled to attend to the conversation but whose restless eagerness shows that he is longing to get back to some more congenial pursuit. If we pursue the notion of ambivalency further, the thought suggests itself that the psychosis reveals the existence of a bisexual attitude. From this point of view the aggressiveness and cruelty of the 'Strengths' may be regarded as an exaggeration of the masculine sexual attitude, and the pleasure in submitting to these aggressions represents the opposite feminine attitude. It is not infrequent for insane cases to have delusions of a bisexual nature; but Mr. A. does not explicitly state this, and his 
notion of personal identity is, of course, not affected by the psychosis. At any rate, the pregnancy phantasy shows that the patient in some instances assumes a definitely feminine rôle; and he sometimes hints that the 'Strengths' subject him to concrete sexual aggressions at night, though he says nothing as to their nature and is most reticent on this subject. How far the masochistic expiations are to be regarded generally as a means of perverted sexual excitement it is impossible to say, and the same comments are applicable here as those made in respect to the sadistic component.

Thus it would seem that this psychosis can be traced to the fact that, while the intellectual development of the patient reached a high level, his emotional life was arrested at a primitive or infantile level. In the emotional sphere the patient failed to grow up, and the question naturally arises as to how far this fixation of libido or life force was due to traumatic environmental influences in childhood. Since the father influence pervades the whole development of the patient to such a remarkable extent, it may be that the psychosis was ultimately due to an unwise upbringing. It is easy for a father to exploit unwittingly a child as a medium for his love of power, and to adopt such an attitude that he irritates him and thereby creates situations which afford him an opportunity for the infliction of punishment. Such an attitude may have unfortunate effects upon the growing mind of a child, the results of which may be incalculable; but to stress unduly the influence of environment in the production of a psychosis may blind us to the influence of inborn factors which have to be taken into account. The biogenetic psychoses give a general impression of inevitability which suggests that they are the product of inborn inferiority; but our present state of knowledge scarcely justifies any dogmatism or fixity of view on this all-important problem. What this case does seem to demonstrate is the disastrous influence upon the personality of a perverted instinctive trend. The whole psychosis may be traced to a wish in the Freudian sense. Savage has used the term 'morbid mental growth' to emphasize the fact that mental disorder may originate from small beginnings, ${ }^{6}$ and we certainly see in this case how an abnormal tendency in childhood gradually influenced Mr. A.'s whole outlook on life, how it moulded his character, wrecked his career, isolated him from friendly contact with other people, impelled him to wander restlessly about the world finding no peace, and how, finally, like a cancerous growth, it invaded the personality and drove him into an asylum. I am well aware that such a view is regarded with disfavour by many psychiatrists. Thus Kraepelin writes in referring to the work of Jung? : "The idea of independent parasitic neoplasms, which on the one hand are completely drawn from the influence of the ego, but on the other hand 
are able wholly to transform it and almost annihilate it, would overthrow such a number of thoroughly ascertained psychological experiences, that its substantiation must in any case be supported by quite other means of proof than has hitherto been the case". In spite of these views I think it is perfectly reasonable to explain the case along the lines suggested. Indeed the case may be said to explain itself. In this psychosis nature herself has revealed those facts which the psychopathologist endeavours to elicit by an artificial process, and I think the revelations of the patient, in which suggestion can altogether be excluded, do much to confirm some of the basic principles advanced by Freud in his various works. This view is expressed with all the more confidence as this investigation was not started to prove or disprove anything, but merely to record the statements of the patient.

The psychosis would thus seem to be the inevitable product of elemental forces beyond the control of the patient As a social unit Mr. A. was a kind of cave-man-perhaps inherently so-and the psychosis may thus be regarded as the natural outcome of a condition of biological inferiority. Modern life provides no adequate outlet for the kind of things the patient would wish to do. All the energy of the organism which should be utilized in the work of social adaption is here absorbed by a craving which from its nature cannot be expressed by actions in relation to the environment. The psychosis has a biological function; it affords a means by which the craving is actualized and finds free expression. It is easy to see that the psychosis brings about a condition of dynamic equilibrium. The insatiable need which ultimately finds expression in the 'Immortal Strengths' derives its energy from the life of the organism and must issue in appropriate motor activities. The structure of the psychosis makes this possible. It has been shown that each hallucinatory suggestion (impulse to action) provokes an immediate response on the part of the patient in the form of expiatory activities, and it is through the medium of these expiations that the energy of the affective craving finds a channel of release. These mental activities involve nascent or actual movements of the organism, and it is by such reactions that the release of tension is constantly effected and a state of equilibrium thereby maintained.

On one occasion Mr. A. remarked, "My mind is fast becoming a Mississippi flow of words. Any one whom the 'Strengths' get hold of will be ultimately reduced to a mass of jumbled up wordings". Perhaps the patient is here predicting with a good deal of truth the terminal stage of the psychosis from which he suffers. This would mean that his abnormal craving gradually absorbs more and more of his energy, and he is forced to perform more and more complex acts 
of expiation. Objectively the patient would become more inaccessible, and perhaps the only evidence of mental activity would be a few apparently meaningless fragments of his apologies. In spite of appearances there would actually be no real deterioration of the personality, and the condition presented would be more accurately described as a progressive narrowing of interest than as a true dementia. Such reflections give some colour to the view that many of our patients who present some such clinical picture as the above are not really demented, but are rather absorbed in matters of greater personal significance to them than the ordinary interests of life.

\section{REFERENCES.}

1 Janet, Les Obsessions et la Psychasthénie, 1903, 138.

2 Devine, "A Study of Hallucinations in a Case of Schizophrenia", Jour. of Ment. Sci., 1921, lxvi, 172. (I am indebted to the Editors of the Journal of Mental Science for permission to publish extracts from this paper, which contains a partial description of the case.)

${ }^{3}$ Maeder, "Sexualität und Epilepsie", Jahrb. f. psychoanalytische u. psychopathologische Forschungen, 1910, i, 119.

4 Jones, Papers on Psychoanalysis, 1920, 455.

5 READ, "Study of Epileptoid States in Soldiers", Jour. Abnorm. Psychol., 1918, xiii.

6Savage, "Morbid Mental Growths", Med. Press and Circ., 1911, May 3.

7 Krafpelin, Dementia Procox and Paraphrenia, 1919, 247. 